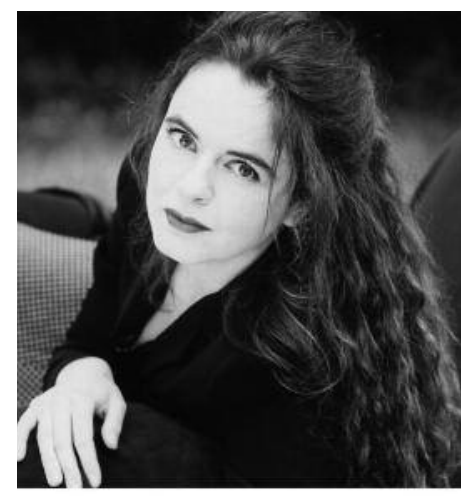

Amélie Nothomb, nacida el 13 de agosto de 1967 en Kobe (Japón) es una escritora belga de lengua francesa. Estudió Filología Románica en la Universidad Libre de Bruselas. Ha vivido en Japón, China, Estados Unidos, Laos, Birmania y Bangladesh. Habla japonés y trabajó como intérprete en Tokio. Relató esta experiencia en su novela Estupor y temblores (Stupeur et tremblements), Gran Premio de Novela de la Academia Francesa en 1999, llevada al cine por Alain Corneau en 2003. Desde 1992, ha publicado una novela cada año. Recibió el Premio Leteo en 2006. Entre sus autores favoritos destacan Mishima, Diderot, Tanizaki, Montherlant, Proust, Celine, Éric-Emmanuel Schmitt, Simon Leys, Jacqueline Harpman, Nathalie Gassel, Yoko Ogawa y Kazuo Ishiguro. Muchas de sus obras tienen carácter autobiográfico y han sido publicadas en España: Hygiène de l'assassin, 1992 (Higiene del asesino, Circe Ediciones, 1996), Le Sabotage amoureux, 1993 (El sabotaje amoroso, Anagrama, 2003), Les Catilinaires, 1995 (Las catilinarias, Circe Ediciones, 1997), Attentat, 1997 (Atentado, Circe Ediciones, 1998), Stupeur et tremblements, 1999 (Estupor y temblores, Anagrama, 2004), Métaphysique des tubes, 2000 (Metafísica de los tubos, Anagrama, 2001), Cosmétique de l'ennemi, 2001 (Cosmética del enemigo, Anagrama, 2003), Robert des noms propres, 2002 (Diccionario de nombres propios, Anagrama, 2004), Antéchrista, 2003 (Antichrista, Anagrama, 2005), Biographie de la faim, 2004 (Biografía del hambre, Anagrama, 2006), Acide Sulfurique, 2005 (Ácido sulfúrico, Anagrama, 2007), Journal d'Hirondelle, 2006 (Diario de Golondrina, Anagrama, 2008) y Ni d'Ève, ni d'Adam, 2007 (Ni de Eva ni de Adán, Anagrama, 2009). 


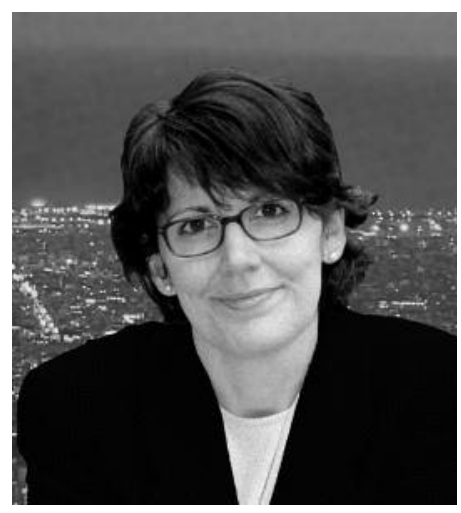

ImMa Monsó i Fornell nace en Lérida en 1959. Estudia Filología Francesa en la Universidad de Barcelona y, más tarde, se especializa en lingüística aplicada en las universidades de Estrasburgo y Caen. En 1996 gana el Premio Ribera d'Ebre de 1996 con su libro de cuentos Si és no és (Mèdol, 1997). El mismo año publicó su primera novela, No se sap mai (Edicions 62, 1996) y en 1998 ve la luz su novela Com unes vacances (premio Prudenci Bertrana, Gerona). Ambas novelas han sido traducidas al castellano y publicadas por Tusquets. Su tercera novela, Tot un caràcter (Edicions de la Magrana, 2001), fue publicada en castellano por Alfaguara. Sus últimos libros son de narraciones. En 2003 publica Millor que no m'ho expliquis, cuentos sobre la pareja, la felicidad, las relaciones familiares y la enfermedad, y en el 2004, Marxem, papà. Aquí no ens hi volen, historias sobre personajes que observan y que, al mismo tiempo, también son observados. Imma Monsó colabora en les páginas del periódico El País y es miembro de la Associació d'Escriptors en Llengua Catalana. 


\title{
AMÉLIE NOTHOMB: LA VIDA EN EL COR DE L'OBRA
}

IMMA MONSÓ

\begin{abstract}
RESUMEN
Breve repaso de la obra de Amélie Nothomb (autora belga nacida en Kobe, Japón en 1967), que pone de relieve la importancia de la biografía personal en las novelas de esta popular autora.

$\Rightarrow$ PALABRAS ClAVE: Autobiografía, narrativa belga en francés.
\end{abstract}

Vaig conèixer literàriament Amélie Nothomb fa uns deu anys, a través de la seva novel.la Les Catilinaires, un dels primers llibres de la seva extensa obra. En aquells anys Nothomb va resultar per a mi una gratíssima sorpresa que sorgia del panorama literari europeu com un bolet singular, una cosa que també em va passar amb Birgit Vanderbeke, a qui vaig conèixer més o menys per aquella època i per l'obra de la qual sento una gran estima. Així és que a partir d'aquell moment vaig continuar llegint totes dues autores, i al llarg del temps he seguit fidelment l'obra de Nothomb, també la de Vanderbeke, menys prolífica que la primera. Vaig conèixer personalment Amélie Nothomb l'any 2006, quan l'autora va visitar Barcelona arran de la publicació de la traducció al català i al castellà de Biographie de la faim (2004). Llavors vaig tenir l'ocasió de presentar-la en un acte a l'Institut Francès de Barcelona, i si destaco la trobada amb la persona és perquè en aquest article pretenc posar de relleu que Amélie Nothomb és una d'aquestes autores en les 
quals vida, obra, personalitat i actitud davant la vida es fonen en una única amalgama de materials impossibles de discernir. Personalment, a més, m'agraden els autors que, com a individus, són una continuïtat de la seva pròpia obra. És el seu cas: quan hom coneix la persona, s'adona que és davant d'un individu plenament integrat en el teixit de la seva pròpia escriptura. Refinada, peculiar, tocada per la gràcia $\mathrm{i}$ amb un elevat grau de cortesia que probablement vol suavitzar els excessos del seu intel.lecte, Amélie Nothomb i la seva obra fan la impressió de ser una sola peça, sense fissures, sense decepcions.

El seu primer llibre clarament autobiogràfic és Le sabotage amoureux (Albin Michel, 1993). En la cronologia de la seva obra és el seu segon llibre, i en ell parla dels anys de la seva infància que van dels cinc als vuit anys, l'època en què el seu pare, ambaixador de Bèlgica, va ser destinat a la Xina procedent del Japó (entre 1972 i 1975). Aquesta trobada amb la Xina va representar per a la petita Amélie una mena de descens als inferns des del cel del refinament nipó.

A Métaphysique des tubes (Albin Michel, 2000), l'autora gosa abordar un període de la vida (dels 0 als 3 anys), del qual és gairebé impossible conservar records. Possiblement és un dels pocs llibres que han estat escrits des de l'òptica d'un bebè: un bebè plàcid amb trets vagament autistes, i per descomptat, omnipotent, com ja Freud i Lacan ens van ensenyar que eren les criatures abans d'arribar a tenir consciència de la seva pròpia identitat. Nothomb narra amb mestratge i amb l'humor que la caracteritza aquest període omnipotència abans de descobrir el llenguatge, i conscient que al lector li costarà de creure en una tan prodigiosa memòria, l'autora sent la necessitat d'assegurar-li que no ha oblidat res del que va tenir veritable importància: 
Je n'ai rien oublié de ce qui en valait la peine: le vert du lac où j’ai appris à nager, l'odeur du jardin, le goût de l'alcool de prune testé en cachette et autres découvertes intellectuelles ${ }^{1}$.

¿Qui gosa contradir-la? Les afirmacions de Nothomb són contundents, i aquesta contundència és part del seu estil literari. No va trigar molt a escriure un altre text autobiogràfic. L'any 1999 publica Estupor $i$ tremolors que descriu l'experiència viscuda a l'edat de vint i tres anys, quan va tornar al Japó esperant trobar-hi el paradís perdut que ella recordava i en comptes d'això es va veure condemnada a treballar en un laberint de malentesos: una empresa que apareix sota el nom inventat de Yumimoto, on la protagonista malda per sobreviure a les ordres d'uns caps que exerceixen el poder duna manera absurda.

Si fins aquí el pes de la biografia en l'obra de l'autora era important, l'any 2004 publica Biographie de la faim, un llibre, de nou, plenament autobiogràfic que parteix d'un postulat interessant on fàcilment hi podem reconèixer el principi de desig enunciat per Freud: sense gana, no hi ha recerca. Sense desig, la vida esdevé un llac immens de tedi. A partir d'aquest inici interessant, l'autora recorre el seu passat de nena i d'adolescent: viatges, bulímia de lectures, període d'anorèxia, dipsomania, etc. I, tanmateix, un lector fidel de la seva obra hi podia reconèixer fàcilment experiències ja narrades en altres llibres anteriors suposadament menys autobiogràfics.

1 No he oblidat res del que valia la pena: el vert del llac on vaig aprendre a nedar, les olors del jardí, l'alcohol de pruna que provava d'amagat $i$ altres descobriments intel.lectuals. Métaphysique des tubes, 41/2. 
Fins a tal punt el pes de la biografia és important que un article d'Hélène Jaccomard, (University of Western Australia, juny 2004) porta per títol La biografia més gran de l'univers: la hiperautobiografia d'Amélie Nothomb. Cal destacar que quan aquest article va ser escrit, Nothomb encara no havia publicat Biografia de la fam, que va sortir a la llum l'any 2006. Potser parlar de «la biografia més gran de l'univers» és exagerat, però sens dubte és significatiu de que Nothomb és el tipus de narradora que sap mirar-se el passat propi i les experiències més desafortunades (com és el cas clarament a Estupor i tremolors), i convertir-les en una experiència de plaer literari per a ella i per als seus lectors. És una mirada intel.ligent, aguda, de vegades finsi tot massa enginyosa, massa brillant, el fruit de la qual és una visió de la realitat presidida per una auto-ironia constant, una singular barreja de tendresa i d'humor àcid. Són aquests recursos, juntament amb un notable domini de la hipèrbole i de la poètica de l'excés, els que capaciten a l'autora per poder sublimar amb aparent facilitat les experiències més desagradables, fins i tot les més abjectes.

Personalment, entre les afinitats que sento amb Amélie Nothomb, m'interessa particularment aquesta: la relació que l'autora manté amb el concepte d'autobiografia. En alguna ocasió ha dit que rebutja les etiquetes de gènere: «Personalment no faig diferències entre els dos gèneres, novel.la autobiogràfica i novel.la no autobiogràfica», ha dit sovint. I, en una entrevista diu que, a la manera d'André Gide, pensa que no hi a res més dissimulador que l'autobiografia: «Penso que em revelo amb molta més veracitat en les meves novel.les no autobiogràfiques que a les que són autobiogràfiques, cosa que no vol pas dir que menteixi», diu l'autora parafrasejant Gide. 
Així doncs, si segons ella, a les obres no autobiogràfiques és on es revela més a fons, podríem dir que, en complementar-les amb les seves obres biogràfiques tindríem la totalitat de l'autora, una autora que se sap exposar amb gosadia i amb generositat.

Per acabar i parlant de generositat, només un retret li he de fer: crec que el conjunt de la seva obra guanyaria si en comptes de publicar d'una manera tan prolífica es prengués més temps per deixar sedimentar les seves històries. L’èxit comercial (o la grafomania que ella confessa sovint) són mals consellers literaris, i potser fora preferible que ens lliurés el seu talent en dosis més concentrades. La facilitat amb què li brollen les històries pot acabar convertint-la en una autora per a adolescents o per a primers lectors. La qual cosa no és que estigui malament;: ja m'agradaria que a les escoles els alumnes llegissin Nothomb en comptes de segons què, però alguns preferiríem una autora que no fes concessions a allò que anomenem «el públic en general», que acostuma a demanar textos d'alt impacte i, en canvi, decidís optar per textos més subtils i per una trajectòria més auto-exigent. En qualsevol cas, penso que alguns dels seus llibres justifiquen plenament la carrera literària d'una narradora que posseeix una visió de la realitat que ho és tot menys banal; una autora que, defugint constantment els tòpics, ha aconseguit crear una col.lecció de petites peces que, per bé que siguin de qualitat irregular, conformen un univers literari únic. 